\title{
Basic Knowledge of Army Troops and their Relatives in Rangpur towards Antibiotic
}

\author{
Nazrina $S^{1}$, Chowdhury $D K P^{2}$, Al Maruf $A^{3}$, Rahman $W^{4}$
}

\begin{abstract}
Introduction: Inappropriate use of antibiotic may create several problems including emergence of drug resistant microorganisms, the rising costs of health-care services and the development of side effects. Misconceptions regarding antibiotic can lead to misuse of antibiotics. So, consumers' knowledge towards antibiotic may play a vital role in the success of treatment process.
\end{abstract}

Objectives: To investigate the level of basic knowledge towards antibiotics among troops of Bangladesh Army and their relatives in Rangpur, Bangladesh.

Materials and Methods: This cross-sectional study was conducted from January to March 2015 for 12 weeks using the structured questionnaire involving 389 respondents attending outdoor of various departments of Combined Military Hospital $(\mathrm{CMH})$, Rangpur. A random knowledge score system was used to assess basic knowledge based on the answers provided.

Results: The mean age of the respondents was 30.434 years $(S D=6.5365)$ with male $(53.47 \%)$ predominance. Out of 389 respondents, $219(56.30 \%)$ respondents had a moderate level of knowledge. Most of the respondents $(89.72 \%)$ could correctly identify that antibiotics are indicated for the treatment of bacterial infections. However, 348(89.46\%) respondents incorrectly thought that antibiotics are also used to treat viral infections. Most of the respondents wrongly believed that antibiotics are indicated to relieve pain $(68.69 \%)$ and reduce fever $(77.38 \%)$. About $270(69.41 \%)$ respondents were aware of antibiotic resistance phenomena in relation to overuse of antibiotics. Age, sex and educational level were significantly associated with knowledge towards antibiotic.
Conclusion: Educational intervention is needed to promote prudent use of antibiotic.

Key-words: Antibiotic, Knowledge, Bangladesh Army troops and their relatives.

\section{Introduction}

Antibiotics are one of the most prescribed medicines and are used liberally by people all over the world ${ }^{1}$. Between 2000 and 2010, total global antibiotic consumption increased by more than 30 percent, from approximately 50 billion to 70 billion standard units, primarily in the developing world ${ }^{2}$. Though for the last seven decades antibiotics have saved million of lives, in the recent past the emergence and spread of several drug resistant microorganisms has rendered the management of many infectious diseases difficult. The world is possibly facing the single biggest threat against antibiotic resistance in the area of infectious diseases $^{3}$. Though resistance to antibiotics is a natural and inevitable biological phenomenon, it is accelerated by inappropriate use of antibiotics ${ }^{4,5}$. Furthermore, inappropriate use of antibiotics produce unwanted allergic reactions, can mask the correct diagnosis and delay appropriate therapy, increase morbidity, mortality and health care costs ${ }^{6}$.

The lack of knowledge may greatly influence the probability of inappropriate use of antibiotics ${ }^{7}$. To solve the problem of inappropriate use of antibiotic, it is necessary to understand patients' knowledge which may facilitate the development of strategies to educate patients ${ }^{8}$. Moreover, consumers can play an important role in reducing the inappropriate and excessive utilization of antibiotic. There are studies among general public regarding knowledge, belief and behaviour on antibiotic use ${ }^{9-13}$. On the other hand, Azevedo MM et al ${ }^{14}$ had conducted study to assess

1. Lt Col Sayeda Nazrina, MBBS, MPhil, Assistant Professor, Dept of Pharmacology and Therapeutics, AFMC, Dhaka 2. Brig Gen Dipak Kumar Paul Chowdhury, MBBS, MPhil, Professor and Head, Dept of Pharmacology and Therapeutics, AFMC, Dhaka 3. Col Abdullah AI Maruf, MBBS, FCPS, Classified Specialist in Anaesthesiology, BGB, Dhaka 4. Lt Col Wahida Rahman, MBBS, MPhil, Assistant Professor, Dept of Pharmacology and Therapeutics, AFMC, Dhaka. 
knowledge of students towards antibiotics. Knowledge of primary and tertiary care attendants towards antibiotics was assessed in other studies ${ }^{15,16}$. This study aimed to investigate the level of basic knowledge towards antibiotic among troops of Bangladesh Army and their relatives in Rangpur, Bangladesh.

\section{Materials and Methods}

This cross-sectional study was conducted over 12 weeks from January to March 2015 using structured questionnaire. Respondents were the patients and their relatives (e.g. patients' family members) attending outdoor of various departments of Combined Military Hospital (CMH), Rangpur. A sample size of 395 was selected for this research with $95 \%$ confidence interval.

A convenience sampling method was adopted. The inclusion criteria were: (1) serving/served Bangladesh Army troops and their relatives (son/daughter/father /mother) (2) adults aged 18 years and over; (3) respondents who were aware of the term 'Antibiotic'. Exclusion criteria was: (1) health care providers or students from any medical/health related field. Respondents were explained about the objectives of the study and verbal permission was taken from them. They participated voluntarily without any problem. On average, the respondents required 15-20 minutes to complete the self-administered questionnaire.

The questionnaire was developed by reviewing earlier studies $^{9-12,17}$. The questions in the questionnaire were grouped broadly into two categories: (a) sociodemographic characteristics of the respondents (b) knowledge on antibiotic. The respondents' knowledge was tested with 12 statements covering role of antibiotics (five statements), identification of antibiotics (two statements), dangers of antibiotics (antibiotic resistance, allergic reaction and side effects: one statement for each) and completion of treatment course (2 statements) with "yes, no, do not know" responses. The questionnaire was constructed by principal author in English language initially and then translated into Bengali language. A pilot study was conducted on 20 volunteers and subsequently some of the questions were reconstructed for better understanding. To assess the knowledge on antibiotics one mark was awarded for each correct answer and zero for each wrong or 'do not know' response, with a maximum obtainable correct score of 12 . A random knowledge score system was used to assess the level of knowledge based on the answers provided. The total knowledge score was determined by three level indicated by poor (0-4), moderate (5-8), good (9-12). All data were analyzed using Microsoft Excel.The influence of demographic characteristics on knowledge was analyzed using Chi Square test. The level of statistical significance was set at $p<0.05$. The data was subjected to simple descriptive statistical analyses including frequency distribution, mean and finally was expressed in percentage.

\section{Results}

A total of 395 questionnaires were distributed to the attendees at the outpatient departments of $\mathrm{CMH}$ Rangpur. However, 6 of the questionnaires were found incomplete and therefore were excluded from the analysis (usable rate of $98.48 \%$ ). In demographic characteristics (Table-I), out of 389 respondents, most of the respondents $(56.04 \%)$ were within the age group of 25-34 years. The mean age of the respondents was 30.434 years $(S D=6.5365)$. Among 389 respondents, $208(53.47 \%)$ were male and $181(46.53 \%)$ were female. Most of the respondents $(92.03 \%)$ had completed at least Secondary School Certificate (SSC) examination. Majority of the respondents were housewives $(46.53 \%)$ followed by Non-commissioned officers (41.64\%), Sainiks $(8.23 \%)$, Retired persons (1.54\%) and others.

Table-I: Distribution by demographic characteristics ( $n=389$ )

\begin{tabular}{|c|c|c|}
\hline Characteristics & Number & Percentage \\
\hline \multicolumn{3}{|l|}{ Age (Years) } \\
\hline $18-24$ & 69 & 17.74 \\
\hline $25-34$ & 218 & 56.04 \\
\hline $35-44$ & 89 & 22.88 \\
\hline $45-54$ & 13 & 3.34 \\
\hline \multicolumn{3}{|l|}{ Gender } \\
\hline Male & 208 & 53.47 \\
\hline Female & 181 & 46.53 \\
\hline \multicolumn{3}{|l|}{ Educational status } \\
\hline Upto Class X & 31 & 7.97 \\
\hline SSC & 187 & 48.07 \\
\hline HSC and above & 171 & 43.96 \\
\hline \multicolumn{3}{|l|}{ Employment status } \\
\hline Housewife & 181 & 46.53 \\
\hline Others(student,businessperson) & 4 & 1.03 \\
\hline Sainik & 32 & 8.23 \\
\hline Non-commissioned officer & 162 & 41.64 \\
\hline Junior commissioned officer & 4 & 1.03 \\
\hline Retired person & 6 & 1.54 \\
\hline
\end{tabular}

More than half of the respondents $(56.30 \%, \mathrm{n}=219)$ had a moderate level of knowledge with a median total knowledge score of 5 out of 12 (Table-II). 
Table-II: Level of knowledge $(n=389)$

\begin{tabular}{|l|c|c|}
\hline Level of knowledge & Number of respondents & Percentage \\
\hline Poor (0-4) & 153 & 39.33 \\
\hline Moderate (5-8) & 219 & 56.30 \\
\hline Good (9-12) & 17 & 4.37 \\
\hline
\end{tabular}

Table-III: Association of demographic characteristics with level of knowledge( $n=389)$

\begin{tabular}{|c|c|c|c|c|}
\hline \multirow[b]{2}{*}{ Characteristics } & & Level of knowledge & & \multirow{2}{*}{$\begin{array}{l}\text { P value } \\
\left(x^{2} \text { test }\right)\end{array}$} \\
\hline & $\begin{array}{c}\text { Poor } \\
\text { (Percentage) }\end{array}$ & $\begin{array}{c}\text { Moderate } \\
\text { (Percentage) }\end{array}$ & $\begin{array}{c}\text { Good } \\
\text { (Percentage) }\end{array}$ & \\
\hline \multicolumn{5}{|l|}{ Sex } \\
\hline Male & $70(33.65)$ & $127(61.06)$ & 11(5.29) & \\
\hline Female & $83(45.86)$ & $92(50.83)$ & $6(3.31)$ & 0.042 \\
\hline \multicolumn{5}{|l|}{ Age (Years) } \\
\hline $18-24$ & $33(47.83)$ & $35(50.72)$ & $1(1.45)$ & \\
\hline $25-34$ & 87 (39.91) & $123(56.42)$ & $8(3.67)$ & \\
\hline $35-44$ & $26(29.21)$ & $57(64.05)$ & $6(6.74)$ & 0.036 \\
\hline $45-54$ & $7(53.85)$ & $4(30.77)$ & $2(15.38)$ & \\
\hline \multicolumn{5}{|c|}{ Educational Status } \\
\hline Upto Class X & $16(51.61)$ & $15(48.39)$ & $0(00)$ & \\
\hline SSC & $73(39.04)$ & $110(58.82)$ & $4(2.14)$ & 0.049 \\
\hline HSC and above & $64(37.43)$ & $94(54.97)$ & $13(7.60)$ & \\
\hline
\end{tabular}

From the assessment of the knowledge regarding the role of antibiotics (Table-IV), it was found that the highest correct response in the knowledge domain was in identifying antibiotics as a means of treating bacterial infection (89.72\%). However, 348(89.46\%) respondents incorrectly thought that antibiotics are used to treat viral infection, which is the highest incorrect response in the knowledge domain. Furthermore, 301(77.38\%) respondents incorrectly thought that antibiotic can cure all infection. For the identification of antibiotics, more than half of the respondents (51.67\%) could correctly identify that paracetamol is not an antibiotic. In addition, about $270(69.41 \%)$ respondents correctly answered that overuse of antibiotics could cause antibiotic resistance.

Table-IV: Knowledge statements $(n=389)$

\begin{tabular}{|c|c|c|c|}
\hline Statement & Correct & Incorrect & Do not know \\
\hline Antibiotics are medicines that can kill bacteria & $349(89.72)$ & $32(8.23)$ & $8(2.05)$ \\
\hline Antibiotics can be used to treat viral infections & $25(6.43)$ & $348(89.46)$ & $16(4.11)$ \\
\hline Antibiotics can cure all infections & $72(18.51)$ & $301(77.38)$ & $16(4.11)$ \\
\hline Antibiotics are indicated to relieve pain & $105(26.99)$ & $268(68.89)$ & $16(4.12)$ \\
\hline Antibiotics are used to reduce fever & $80(20.56)$ & $205(52.70)$ & $104(26.74)$ \\
\hline Penicillin is an antibiotic & $175(44.99)$ & $114(29.30)$ & $100(25.71)$ \\
\hline Paracetamol is an antibiotic & $201(51.67)$ & $148(38.05)$ & $40(10.28)$ \\
\hline 0veruse of antibiotics can cause antibiotic resistance & $270(69.41)$ & $90(23.14)$ & $29(7.45)$ \\
\hline Antibiotics may cause allergic reaction. & $167(42.93)$ & $127(32.65)$ & $95(24.42)$ \\
\hline Antibiotics do not cause side effects & $118(33.33)$ & $212(54.50)$ & $59(15.17)$ \\
\hline Taking less antibiotic than prescribed is healthier than taking the full course prescribed. & $220(56.56)$ & $126(32.39)$ & $43(11.05)$ \\
\hline Taking an antibiotic should be stopped when symptoms are improving & $164(42.16)$ & $200(51.41)$ & $25(6.43)$ \\
\hline
\end{tabular}

Figure-l shows most of the respondents $(78.66 \%)$ got information about antibiotics from doctors. Other sources of information includes medical assistant (MA) $(9.25 \%)$, nurse (3.60\%), television and newspapers $(6.43 \%)$ and others. 


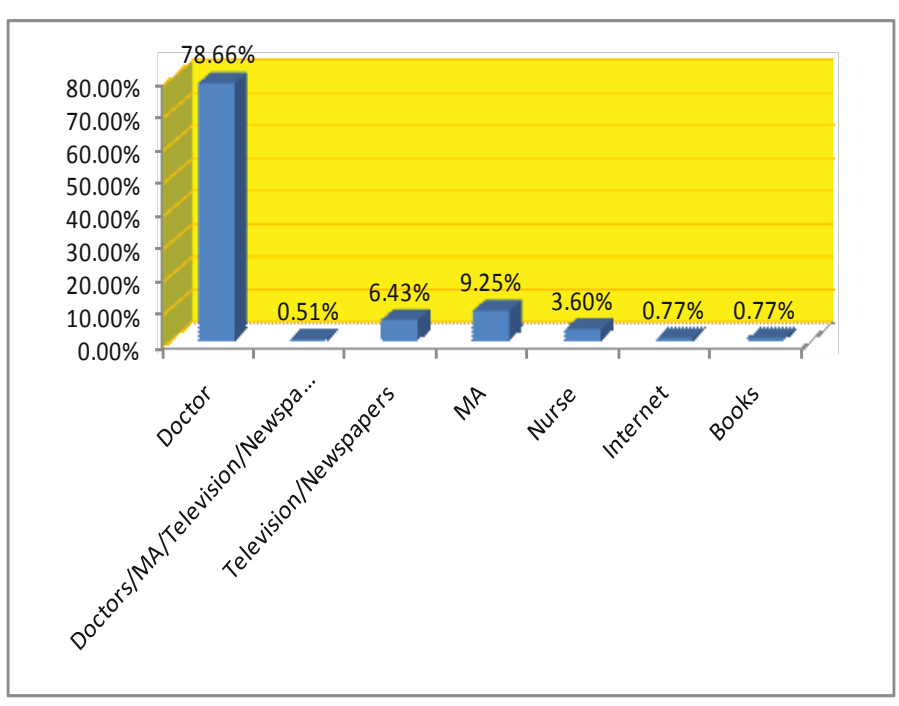

Fig-I: Percentage of participants by sources of information about antibiotic.

\section{Discussion}

This study found respondents have superficial knowledge regarding antibiotics. There is a great confusion regarding how antibiotic works against diseases. Most of them knew that antibiotics are effective against bacterial infections (89.72\%), but had inappropriate knowledge regarding antibiotic's effectiveness for viral infections. More than half of the respondents $(89.46 \%)$ wrongly believed that antibiotics can be used to treat viral infections. This finding is comparable with a study conducted in Malaysia $(83 \%)$ by Lim KK and Teh $\mathrm{CC}^{12}$ but lower proportions were observed by McNulty CA et $\mathrm{al}^{9}$ in Britain (54\%), by Widayati A et $\mathrm{al}^{11}$ in Indonesia (71\%).

In this study, most of the respondents (77.38\%) wrongly believed that antibiotics can cure all infections. In contrast, this misconception was comparatively low in previous studies by Widayati $\mathrm{A}$ et $\mathrm{al}^{11}$ and $\mathrm{Oh} \mathrm{AL}$ et $\mathrm{al}^{10}$ which were $40 \%$ and $25 \%$ respectively. Moreover, a study carried out in Bangladesh by Saha MR et al showed, 30\% participants thought that antibiotics can be used in any disease ${ }^{16}$. Confusion persisted when most respondents of this study wrongly believed that antibiotics are indicated to relieve pain $(68.89 \%)$ and reduce fever $(77.38 \%)$. On the other hand, these findings were comparatively low $(51 \%$ and $46.6 \%$ respectively) in a study by $\mathrm{Oh} A L$ et al ${ }^{10}$ in 2009. More than half of the respondents failed to identify penicillin as an antibiotic and lacked the knowledge to differentiate between antibiotic and other medicine, eg paracetamol. This finding is consistent with the study by Oh AL et al, which reported that $56.9 \%$ respondents identified paracetamol as antibiotic $^{10}$. Two hundred and seventy (69.41\%) respondents had the knowledge regarding risk of overusing antibiotic such as antibiotic resistance. But as it was structured Questionnaire, their knowledge regarding definition of antibiotic resistance could not come into view. A study by $\mathrm{Oh}$ $\mathrm{AL}$ et $\mathrm{al}^{10}$ found that $59.1 \%$ general people in Malaysia knew overuse of antibiotic can cause antibiotic resistance.

More than half of the respondents $(56.56 \%)$ had correct knowledge to complete the full course of antibiotics which is comparable to previous studies done in Hong Kong $(58 \%)$ by You JHS et $\mathrm{al}^{13}$ and Taiwan $\left(50.1 \%\right.$ ) by Chen $\mathrm{C}$ et $\mathrm{al}^{18}$. Oh AL et $\mathrm{al}^{10}$ in their study observed that higher proportion of the respondents $(71.1 \%)$ had correct knowledge to complete the full course of antibiotics. A survey by Pechère $\mathrm{JC}$ et al ${ }^{19}$ carried out in 9 countries noticed that $69 \%$ of the patients claimed to have taken the course until the end (United Kingdom, 90\%; Thailand, $53 \%$ ). A study by Saha MR et al $^{16}$ carried out in outpatient departments of 3 tertiary hospitals in Bangladesh showed that $51.71 \%$ of the patients did not complete the full course of therapy.

One hundred and sixty seven $(42.93 \%)$ respondents correctly answered that antibiotic may cause allergic reaction. In a study by $\mathrm{O} A \mathrm{~L}$ et al, this finding was slightly higher $(53.9 \%)^{10}$. In comparison, Lim KK and Teh CC in their study observed that the majority $(82.5 \%)$ were aware about the allergic reactions caused by antibiotics ${ }^{12}$.

One hundred and eighty (33.39\%) respondents wrongly believed taking less antibiotic than prescribed is healthier than taking the full course prescribed which is similar to the study by Lim KK and Teh $\mathrm{CC}^{12}$. In this study half of the respondents $(51.41 \%)$ wrongly thought that antibiotic should be stopped when symptoms improved. In comparison, this percentage is comparatively low in similar studies ${ }^{10,12,20}$. In study by Saha MR et $\mathrm{al}^{16}$ in Bangladesh, $39.14 \%$ of the respondents replied that they stopped antibiotics when the symptoms disappeared. 
Taking suboptimal dose of antibiotic is one of the causes of increasing antibiotic resistance ${ }^{21}$. Higher educational level is significantly associated with increased knowledge towards antibiotic which have already been evidenced in previous studies ${ }^{10,13,17,22}$

However, this study had some limitations. A convenient sampling method was utilized in this study, it might create the possibilities for selection bias. Moreover, this study only emphasized consumers' knowledge regarding antibiotic. Further study may be carried out regarding their behaviour and attitude towards antibiotic use.

\section{Conclusion}

This study identified the area of misperceptions towards antibiotics among the respondents. There are scopes for improving the consumers' knowledge of antibiotic use through educational interventions. Strategy should be made in this aspect among army troops and their relatives immediately. According to findings of present study, emphasis may be given more to female, older age, and those with lower formal education. On the other hand, doctors must explain their prescribing decision to the patients in detail. Other health care professionals should inform correctly about antibiotics during dispensing. Moreover, a policy could be taken at government level to grow awareness regarding antibiotics through campaign, seminar, symposium etc.

\section{References}

1. Gelband H, Miller-Petrie M, Pant $S$ et al. The State of the World's Antibiotics, 2015. Center for Disease Dynamics, Economics and Policy. Available at: http://cddep.org/ publications/ state_worlds_antibiotics_2015, accessed on Feb 20, 2016.

2. Van Boeckel TP, Gandra S, Ashok A et al. Laxminarayan R Global antibiotic consumption 2000 to 2010: an analysis of national pharmaceutical sales data. Lancet Infect Dis 2014 Aug; 14(8):742-50.

3. World health organization. Regional Strategy on Prevention and Containment of Antimicrobial Resistance 2010-2015. World health organization; 2015:3.

4. World Health Organization.WHO Interventions and strategies to improve the use of antimicrobials in developing countries. World Health Organization 2001:15.

5. Bronzwaer SLAM, Cars O, Buchholz U et al. The Relationship between Antimicrobial Use and Antimicrobial Resistance in Europe. Emerg Infect Dis 2002 Marc; 8(3):278-82.

6. Jawetz E. Antimicrobial chemotherapy. Annu Rev Microbial $1956 ; 10: 85-114$.
7. Kandakai TL, Price JH, Telljohann SK et al. Knowledge, beliefs and use of prescribed antibiotic medications among low-socioeconomic African Americans. J Natl Med Assoc 1996 May; 88(5):289-94.

8. Vanden Eng J, Marcus R, Hadler JL et al. Consumer attitudes and use of antibiotics. Emerg Infect Dis 2003; 9:1128-35.

9. McNulty CA, Boyle P, Nichols T et al. Don't wear me outthe public's knowledge of and attitude to antibiotic use. J Antimicrob Chemother 2007; 59:727-38.

10. Oh AL, Hassali MA, Al-Haddad MS et al. Public knowledge and attitudes towards antibiotic usage: a cross-sectional study among the general public in the state of Penang, Malaysia. J Infect Dev Ctries 2011; 5:338-47.

11.Widayati A, Suryawati S, de Crespigny C et al. Knowledge and beliefs about antibiotics among people in Yogyakarta City Indonesia: a cross sectional population-based survey. Antimicrob Resist Infect Control 2012; 1:38.

12. Lim KK, Teh CC. A Cross Sectional Study of Public Knowledge and Attitude towards Antibiotics in Putrajaya, Malaysia. Southern Med Review 2012 Dec; 5(2):26-33.

13. You JHS, Yau B, Choi KC et al. Public knowledge, attitudes and behavior on antibiotic use: A telephone survey in Hong Kong. Infection 2008; 36:153-7.

14. Azevedo MM, Pinheiro C, Yaphe J et al. Portuguese students' knowledge of antibiotics: a cross-sectional study of secondary school and university students in Braga.BMC Public Health 2009 Sep 23; 9:359.

15. Ilhan MN, Durukan E, Ilhan SO et al. Self-medication with antibiotics: Questionnaire survey among primary care center attendants. Pharmacoepidemiol Drug Saf 2009 Dec; 18(12): 1150-7.

16. Saha MR, Sarwar S, Shill MC et al. Patients' Knowledge and Awareness towards Use of Antibiotics in Bangladesh: A Cross-sectional Study Conducted in Three Tertiary Healthcare Centers in Bangladesh. SJ Pharm Sci 2010; 3(1):54-8.

17. Andre' $M$, Vernby A, Berg $J$ et al. A survey of public knowledge and awareness related to antibiotic use and resistance in Sweden. J Antimicrob Chemother 2010; 65: 1292-6.

18. Chen $\mathrm{C}$, Chen YM, Hwang $\mathrm{KL}$ et al. Behavior, attitudes and knowledge about antibiotic usage among residents of Changhua, Taiwan. J Microbiol Immunol Infect 2005; 38:53-9.

19. Pechère JC, Hughes D, Kardas $P$ et al. Non-compliance with antibiotic therapy for acute community infections: a global survey. Int J Antimicrob Agents 2007 Mar; 29(3):245-53.

20. Jose J, Jimmy B, Alsabahi AG et al. A study assessing public knowledge, belief and behavior of antibiotic use in an omani population.Oman Med J 2013 Sep; 28(5):324-30.

21. Thomas JK, Forrest A, Bhavnani SM et al. Pharmacodynamic evaluation of factors associated with the development of bacterial resistance in acutely ill patients during therapy. Antimicrob Agents Chemother 1998; 42:521-7.

22. Napolitano F, Izzo MT, Di Giuseppe G et al. Public knowledge, attitudes and experience regarding the use of antibiotics in Italy. PLoS One 2013; 8(12):e84177. 